\title{
Lobular Patterns of Cerebellar Activation in Verbal Working- Memory and Finger-Tapping Tasks as Revealed by Functional MRI
}

\author{
John E. Desmond, ${ }^{1}$ John D. E. Gabrieli, ${ }^{1}$ Anthony D. Wagner, ${ }^{1}$ Bruce L. Ginier, ${ }^{2}$ and Gary H. Glover ${ }^{3}$ \\ Departments of ${ }^{1}$ Psychology and ${ }^{3}$ Radiology, Stanford University, Stanford, California 94305, and ${ }^{2}$ Radiology \\ Department, Saint Agnes Medical Center, Fresno, California 93720
}

The lobular distributions of functional activation of the cerebellum during verbal working-memory and finger movement tasks were investigated using functional magnetic resonance imaging (fMRl). Relative to a rest control, finger tapping of the right hand produced ipsilateral-increased activation in HIV/HV [Roman numeral designations based on Larsell's (Larsell and Jansen, 1972) nomenclature] and HVI and weaker activation in HVIII that was stronger on the ipsilateral side. For a working-memory task, subjects were asked to remember six (high load) or one (low load) visually presented letters across a brief delay. To assess the motoric aspects of rehearsal in the absence of working memory, we asked the subjects to repeatedly read subvocally six or one letters at a rate that approximated the internally generated rehearsal of working memory (motoric rehearsal task). For both tasks, bilateral regions of the superior cerebellar hemispheres (left superior HVIIA and right $\mathrm{HVI}$ ) and portions of posterior vermis ( $\mathrm{VI}$ and superior VIIA) exhibited increased activation during high relative to low load conditions. In contrast, the right inferior cerebellar hemisphere (HVIIB) exhibited this load effect only during the working-memory task. We hypothesize that HVI and superior HVIIA activation represents input from the articulatory control system of working memory from the frontal lobes and that HVIIB activation is derived from the phonological store in temporal and parietal regions. From these inputs, the cerebellum could compute the discrepancy between actual and intended phonological rehearsal and use this information to update a feedforward command to the frontal lobes, thereby facilitating the phonological loop.

Key words: cerebellum; verbal working memory; cognition; brain mapping; functional magnetic resonance imaging; finger tapping
Convergent reports of cognitive deficits in cerebellar-damaged patients and cerebellar activation in functional-imaging studies of cognition indicate that the cerebellum participates not only in motor processes but also in cognitive processes (e.g., see Leiner et al., 1993, 1995; Fiez, 1996; Allen et al., 1997). The specific anatomical basis of cognitive processing in the cerebellum is, however, poorly understood. The cerebellum is a complex structure comprised of 10 hemispheric and vermian lobules that differ in their afferent and efferent connections. It is difficult to associate particular deficits with specific cerebellar locations because lesions often traverse lobular boundaries. Functional imaging offers an opportunity to specify the anatomical loci of cognitive processes in the cerebellum. However, most cognitive-imaging studies have not included the full cerebellum because of field-ofview limitations (Jenkins and Frackowiak, 1993), and little is known regarding the anatomical basis of cognitive cerebellar activation beyond averaged stereotaxic coordinates.

The present functional magnetic resonance imaging (fMRI) study therefore focused exclusively on the cerebellum to characterize the lobular and deep nuclear activation patterns for a specific cognitive process, verbal working memory, for which activation in the cerebellum is known to occur (see Table 1). Working memory, a process in which information is temporarily maintained, was examined because of its hypothesized funda-

Received May 27, 1997; revised Sept. 29, 1997; accepted Oct. 2, 1997.

This work was supported by National Institute of Neurological Diseases and Stroke Grant F32NS09628, National Institute on Aging Grant AG12995, National Institute on Alcohol Abuse and Alcoholism Grant AA10723, and by grants from the Stanford Office of Technology and Licensing and the Lucas Foundation.

Correspondence should be addressed to Dr. John E. Desmond, Department of Psychology, Stanford University, Stanford, CA 94305.

Copyright (C) 1997 Society for Neuroscience $0270-6474 / 97 / 179675-11 \$ 05.00 / 0$ mental contribution to many cognitive functions, including language comprehension and reasoning (Baddeley, 1992; Just and Carpenter, 1992). Given that cerebellar output influences prefrontal regions considered to be involved in working memory (Middleton and Strick, 1994), some of the cognitive impairment observed in cerebellar patients may be attributable to dysfunctional working memory. In addition, neocortical activations during verbal working memory have been well characterized (for review, see Fiez et al., 1996) and interpreted in the context of a cognitive model of working memory (Paulesu et al., 1993). Therefore, anatomically specified cognitive activations in the cerebellum occurring during verbal working memory may be integrated into a theoretical framework that combines a psychological model with knowledge about corticocerebellar circuitry.

Cerebellar lobular activation was investigated using three tasks. The first task, finger tapping, was included to validate our localization of activation by comparison with electrophysiological data obtained from animals (Adrian, 1943; Snider and Stowell, 1944; Welker et al., 1988). The second task, working memory, examined activation caused by memory load by varying the number of stimuli (letters) that subjects had to keep in mind across a brief delay. The third task, motoric rehearsal, did not require remembering any letters but closely resembled the motoric aspects of rehearsal in the working-memory task. Comparison of motoric rehearsal and working-memory activations was used to evaluate whether activation attributed to memory load could be explained by articulatory motor differences in rehearsal load.

\section{MATERIALS AND METHODS}

Subjects. Nine right-handed subjects, six males and three females, gave their informed consent to participate in this study, which was approved by the Institutional Review Board at Stanford University. The average age 


\section{A Stimulus Timing: Motoric Rehearsal}

\begin{tabular}{|c|c|c|c|c|c|c|}
\hline $\begin{array}{l}\text { High } \\
\text { Load }\end{array}$ & $\begin{array}{c}(\mathbf{M} \mathbf{K} \mathbf{S}) \\
\stackrel{+}{\mathbf{Z}} \mathbf{Q})\end{array}$ & $\begin{array}{c}(\mathbf{M} \mathrm{K} S) \\
\stackrel{+}{\mathrm{Z}} \mathbf{Q})\end{array}$ & $\begin{array}{c}(\mathbf{M ~ K ~ S}) \\
\stackrel{+}{\mathbf{Z}} \mathbf{Q})\end{array}$ & $\begin{array}{c}(\mathbf{M} \mathbf{K} S) \\
\stackrel{+}{\mathbf{Z}} \mathbf{Q})\end{array}$ & press & \\
\hline & $1.35 \mathrm{~s}$ & $1.35 \mathrm{~s}$ & $1.35 \mathrm{~s}$ & $1.35 \mathrm{~s}$ & $1.0 \mathrm{~s}$ & \\
\hline & 0.2 & & & $75 \mathrm{~s}$ & $75 \mathrm{~s}$ & $\overline{0.5 \mathrm{~s}}$ \\
\hline & $\begin{array}{l}\text { Read } \\
6 \text { Letters }\end{array}$ & $\begin{array}{c}\text { Read } \\
6 \text { Letters }\end{array}$ & $\begin{array}{c}\text { Read } \\
6 \text { Letters }\end{array}$ & $\begin{array}{c}\text { Read } \\
6 \text { Letters }\end{array}$ & $\begin{array}{r}\text { Foll } \\
\text { instruc }\end{array}$ & $\begin{array}{l}\text { ow } \\
\text { tions }\end{array}$ \\
\hline $\begin{array}{l}\text { Low } \\
\text { Load }\end{array}$ & $\begin{array}{l}\text { (B) } \mathbf{R} \quad \mathbf{L} \\
\stackrel{+}{\mathbf{G}} \\
\mathbf{N}\end{array}$ & 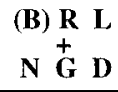 & 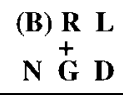 & $\begin{array}{ccc}\text { (B) } & \mathbf{R} & \mathrm{L} \\
& \stackrel{+}{\mathrm{G}} & \mathrm{D}\end{array}$ & press & \\
\hline & $1.35 \mathrm{~s}$ & $1.35 \mathrm{~s}$ & $1.35 \mathrm{~s}$ & $1.35 \mathrm{~s}$ & 1.0 & \\
\hline & & & & $75 \mathrm{~s}$ & $75 \mathrm{~s}$ & \\
\hline & 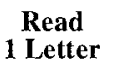 & $\begin{array}{l}\text { Read } \\
1 \text { Letter }\end{array}$ & $\begin{array}{l}\text { Read } \\
1 \text { Letter }\end{array}$ & $\begin{array}{c}\text { Read } \\
1 \text { Letter }\end{array}$ & $\begin{array}{r}\text { Fol } \\
\text { instru }\end{array}$ & ions \\
\hline
\end{tabular}

\section{B Stimulus Timing: Working Memory}

\begin{tabular}{|c|c|c|c|}
\hline \multicolumn{2}{|c|}{ High $\quad\left(\begin{array}{lll}\mathbf{X} & \mathbf{J} & \mathbf{F}\end{array}\right)$} & & f \\
\hline & $1.5 \mathrm{~s}$ & $5.0 \mathrm{~s}$ & $1.0 \mathrm{~s} 0.5 \mathrm{~s}$ \\
\hline & $\begin{array}{l}\text { Read } \\
6 \text { Letters }\end{array}$ & $\begin{array}{l}\text { Remember } \\
6 \text { Letters }\end{array}$ & $\begin{array}{c}\text { Respond if } \\
\text { probe is a match }\end{array}$ \\
\hline
\end{tabular}

\begin{tabular}{|c|c|c|c|}
\hline $\begin{array}{l}\text { Low } \\
\text { Load }\end{array}$ & $\begin{array}{l}\mathbf{R} \underset{\mathbf{P}}{\mathbf{+}} \\
\mathbf{L}(\stackrel{\mathbf{K}}{)}) \mathbf{X}\end{array}$ & & $\mathbf{r}$ \\
\hline & $1.5 \mathrm{~s}$ & $5.0 \mathrm{~s}$ & $1.0 \mathrm{~s} 0.5 \mathrm{~s}$ \\
\hline & $\begin{array}{l}\text { Read } \\
1 \text { Letter }\end{array}$ & $\begin{array}{l}\text { Remember } \\
1 \text { Letter }\end{array}$ & $\begin{array}{l}\text { Respond if } \\
\text { probe is a match }\end{array}$ \\
\hline
\end{tabular}

Figure 1. Timing diagrams for the motoric rehearsal $(A)$ and workingmemory $(B)$ tasks used in this study.

of the subjects was $37.0 \pm 9.2$ years $( \pm \mathrm{SD})$. Eight subjects were scanned under the working-memory and motoric rehearsal tasks. Of these subjects, four subjects also received the finger-tapping task. The ninth subject only received the finger-tapping task.

Stimuli. Stimuli were generated from a Macintosh computer (Apple Computer, Cupertino, CA) using PsyScope software (Cohen et al., 1993) and were visually presented to the subject in the scanner by backprojecting the images, via a magnet-compatible projector (Resonance Technology, Van Nuys, CA), onto a screen located above the subject's neck. Visual images were viewed from a mirror mounted above the subject's head.

Stimuli for the working-memory and motoric rehearsal tasks consisted of arrays of six uppercase consonant letters, arranged in two rows of three letters, with a plus symbol centrally placed between the two rows. The consonants were randomly generated such that six different letters appeared in each stimulus. The six-letter arrays were of two types, high load and low load, and alternating blocks of each trial type (four trials/block) were presented. The high load stimulus had all six letters bracketed by parentheses, whereas the low load stimulus had only one letter in parentheses. For the low load stimuli, the position of the letter in parentheses varied randomly across all six possible positions. Stimuli used for the high and low load conditions were counterbalanced, as was whether the high or low load condition occurred first.

Tasks. For the finger-tapping task, subjects were asked to touch their right thumb to each finger of the right hand in sequence repetitively. Thirty seconds of tapping were alternated with $30 \mathrm{sec}$ of rest in each of six cycles. A visual instruction ("go" for tapping and "no" for rest) cued the subject when to start and stop.

For the motoric rehearsal task, subjects were instructed to read subvocally the letters enclosed in parentheses. To duplicate the amount of rehearsal that occurs in the working-memory task, we flashed the arrays

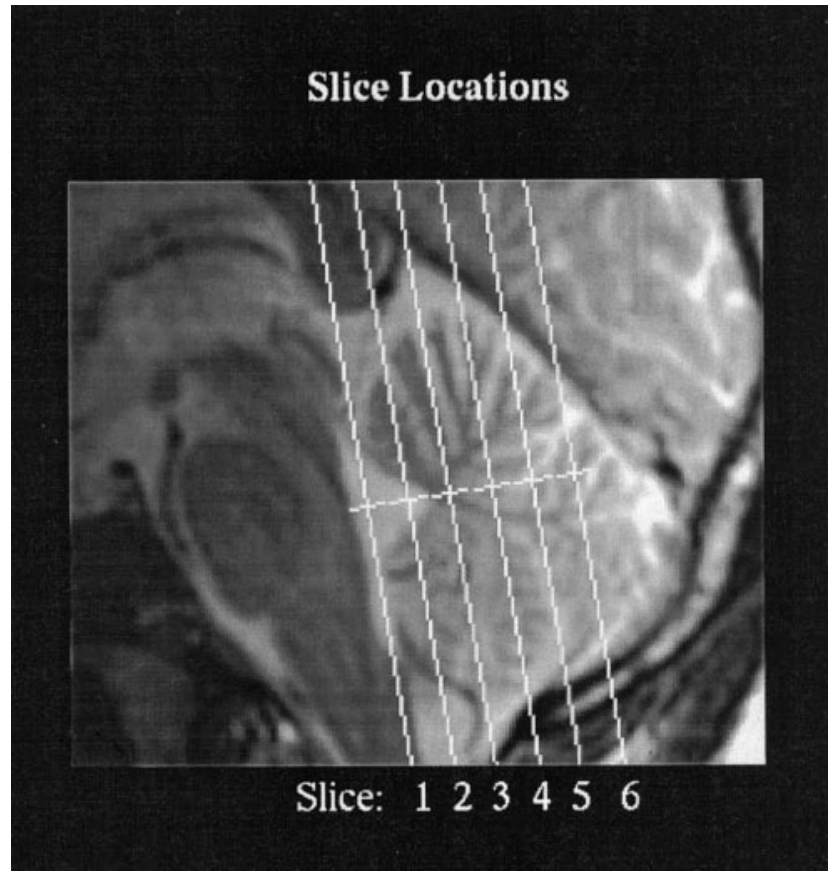

Figure 2. Midline sagittal section illustrating the locations of the six planes acquired during the fMRI experiments.

on and off the screen a total of four times per trial (the same array each time), and the subject was instructed to read the appropriate number of letters (six for high load and one for low load) on each presentation. Four presentations were used because a pilot study of the working-memory task, in which the subject was asked to rehearse aloud, indicated that subjects had sufficient time for this many rehearsals before the probe stimulus was presented. After four presentations of the array, the instruction "press" or "no press" appeared, indicating whether the subject should squeeze a pneumatic response bulb with the right hand. This requirement was included to duplicate the decision and motor components of the working-memory task. To reduce the likelihood that subjects would try to remember the letters during the motoric rehearsal task, we always presented this task before the working-memory task and, thus, before subjects were ever cued to hold letters in memory. Figure $1 \mathrm{~A}$ illustrates the design and timing of the motoric rehearsal task.

For the working-memory task, subjects were instructed to remember the letters enclosed in parentheses. The array was presented only once to the subjects, and this was followed by a $5 \mathrm{sec}$ delay, as illustrated in Figure $1 B$. After this delay, a probe stimulus, consisting of one lowercase consonant letter, was presented. For the high load condition, this probe matched one of the six letters in the array on half of the trials. For the low load condition, the probe matched the single letter in parentheses on half of the trials. For the remaining no-match trials, the probe either matched one of the five letters that were not in parentheses in the array or did not match any letter in the array. Subjects were instructed to squeeze the pneumatic bulb when the probe letter matched a letter that appeared in parentheses. Each trial of the motoric rehearsal or working-memory tasks was $8.0 \mathrm{sec}$ in duration (see Fig. 1). In each experiment there were four trials in each $32 \mathrm{sec}$ block. Six cycles (12 blocks) were presented for $6.4 \mathrm{~min}$.

Data acquisition and analysis Imaging was performed with a $1.5 \mathrm{~T}$ whole-body MRI scanner (General Electric Medical Systems Signa, revision 5.3, Waukesha, WI). For functional imaging, a single local receive coil 5 inches in diameter was positioned under the back of the head to obtain activation signals from the cerebellum. Head movement was minimized using a "bite bar" that was formed with the subject's dental impression. A T2*-sensitive gradient echo spiral sequence (Meyer et al., 1992) was used for functional imaging with the following parameters: repetition time (TR), $402 \mathrm{msec}$; echo time (TE), $40 \mathrm{msec}$; and flip angle, $35^{\circ}$. Ten interleaves were obtained for each image, so the total acquisition time per image was $4.02 \mathrm{sec}$. Six 5 -mm-thick slices (in-plane resolution of $1.8-2.3 \mathrm{~mm}$ and $1 \mathrm{~mm}$ interslice interval) were acquired in oblique coronal planes that were parallel to the brainstem, as illustrated 


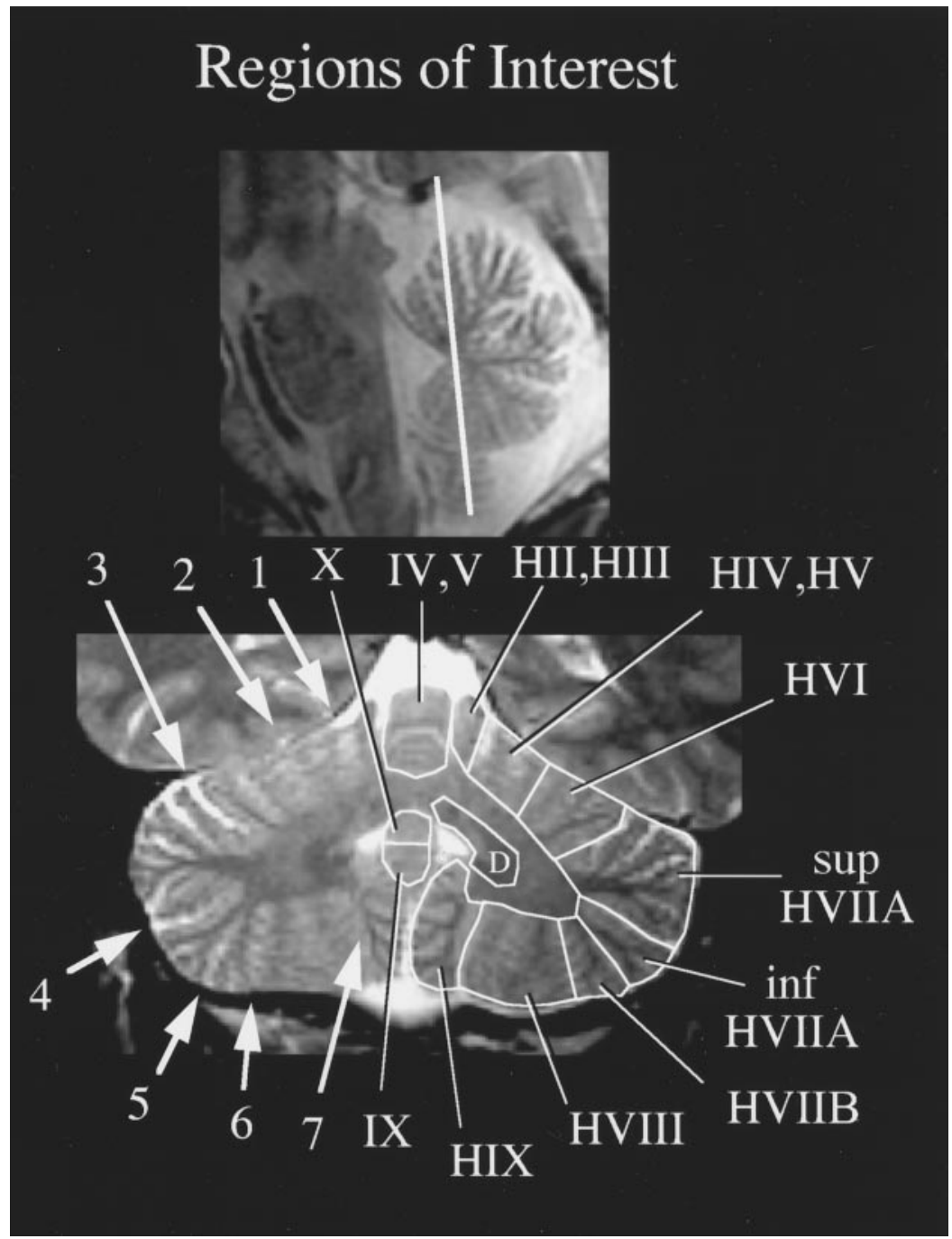

Figure 3. An example of ROI identification on a T2weighted oblique coronal section. The location of the section is illustrated on the sagittal localizer image (top). Fissures used to identify lobular boundaries are indicated on the left side of the oblique coronal section (bottom), and numbered arrows refer to the following: 1, preculminate fissure; 2, primary fissure; 3 , superior posterior fissure; 4 , horizontal fissure; 5, inferior posterior fissure; 6 , inferior anterior fissure; and 7 , secondary fissure. ROIs for this section are depicted on the right side, and Roman numeral designations are based on Larsell's (Larsell and Jansen, 1972) nomenclature (the ROI labeled $D$ represents the deep nuclei, probably the emboliform as well as the dentate nucleus); sup, superior; inf, inferior. in Figure 2, and 96 (for working-memory and motoric rehearsal tasks) or 90 (for the finger-tapping task) images per slice were acquired continuously for the duration of each experiment. T2-weighted anatomy images were obtained in the same plane as the functional images using a fast spin echo pulse sequence and the following parameters: TR, $3000 \mathrm{msec}$; TE, 85 msec; echo train length, 8; number of excitations, 1 ; and $256 \times 192$ matrix. Pixels that were found to be significantly activated during the functional scan were overlaid on these structural images. A set of T2weighted sagittal images covering the entire cerebellum (5-mm-thick contiguous slices) was also obtained.

For data analysis, image reconstruction was performed off-line by transferring the raw data to a Sun SparcStation (Sun Microsystems, Mountain View, CA). The data were resampled into a Cartesian matrix and then processed with a two-dimensional fast Fourier transform. The reconstructed image files were then Gaussian-filtered spatially using a full width at half-maximum of $4.1 \mathrm{~mm}$ to extract greater signal-to-noise and to compensate for between-subject anatomical variability in making the averaged functional map. The time series of each pixel were correlated with a reference waveform and transformed into a $Z$ score map, SPM $\{Z\}$ (Friston et al., 1994). The waveform was calculated by convolving a square wave representing the time course of the alternating conditions (high and low load or tapping and rest for the present study) with a data-derived estimate of the hemodynamic response function. $\operatorname{SPM}\{Z\}$ map averaging and a subject-by-subject-based region of interest (ROI) analysis were used to analyze patterns of functional activation across subjects. Averaging was performed by first creating an outline of each oblique coronal section using a T2-weighted anatomy image of a representative subject to form a template for that slice. Then each subject's functional map at each section was transformed into the region specified by the template as described previously (Desmond et al., 1995). This procedure consisted of the following steps: (1) translating, scaling, and rotating the functional map to match the centroid and dimensions of the template; (2) defining a matching set of points around the perimeter of the functional map and that of the template; (3) creating a grid of points from the perimeter points of the functional map and a corresponding grid on the template such that a one-to-one mapping existed for the grid points in each set; and (4) mapping the values from the grid points of the functional image to the grid points of the template.

The ROI-based analysis was accomplished by identifying on each slice all relevant fissures that separate the cerebellar lobules: the preculminate fissure, the primary fissure, the superior posterior fissure, the horizontal fissure, the inferior posterior fissure, the inferior anterior fissure, and the secondary fissure. These fissures appeared as bright bands on T2weighted images as illustrated in Figure 3. Cerebellar anatomical determinations were guided by published atlases (Courchesne et al., 1989; Press et al., 1989, 1990; Duvernoy, 1995). Numeric lobule identification is based on Larsell's nomenclature (Larsell and Jansen, 1972). To guide identification of cerebellar regions further, a customized program was written to solve the transformation between the computer screen coordinate system and the $x, y$, and $z$ coordinates provided by the scanner. Using this transformation, it was possible to position the mouse cursor on an oblique coronal section, convert the screen coordinate into a scanner coordinate, and then use the inverse screen-to-scanner transformation to localize the same coordinate on a different set of anatomical (sagittal) images. Correlating anatomical loci across the two sets of orthogonal anatomical images facilitated lobule identification. The deep cerebellar nuclei were visible on the T2-weighted images as dark U-shaped structures embedded within the corpus medullare. Regions of interest were manually outlined in the absence of any functional activation. For each 


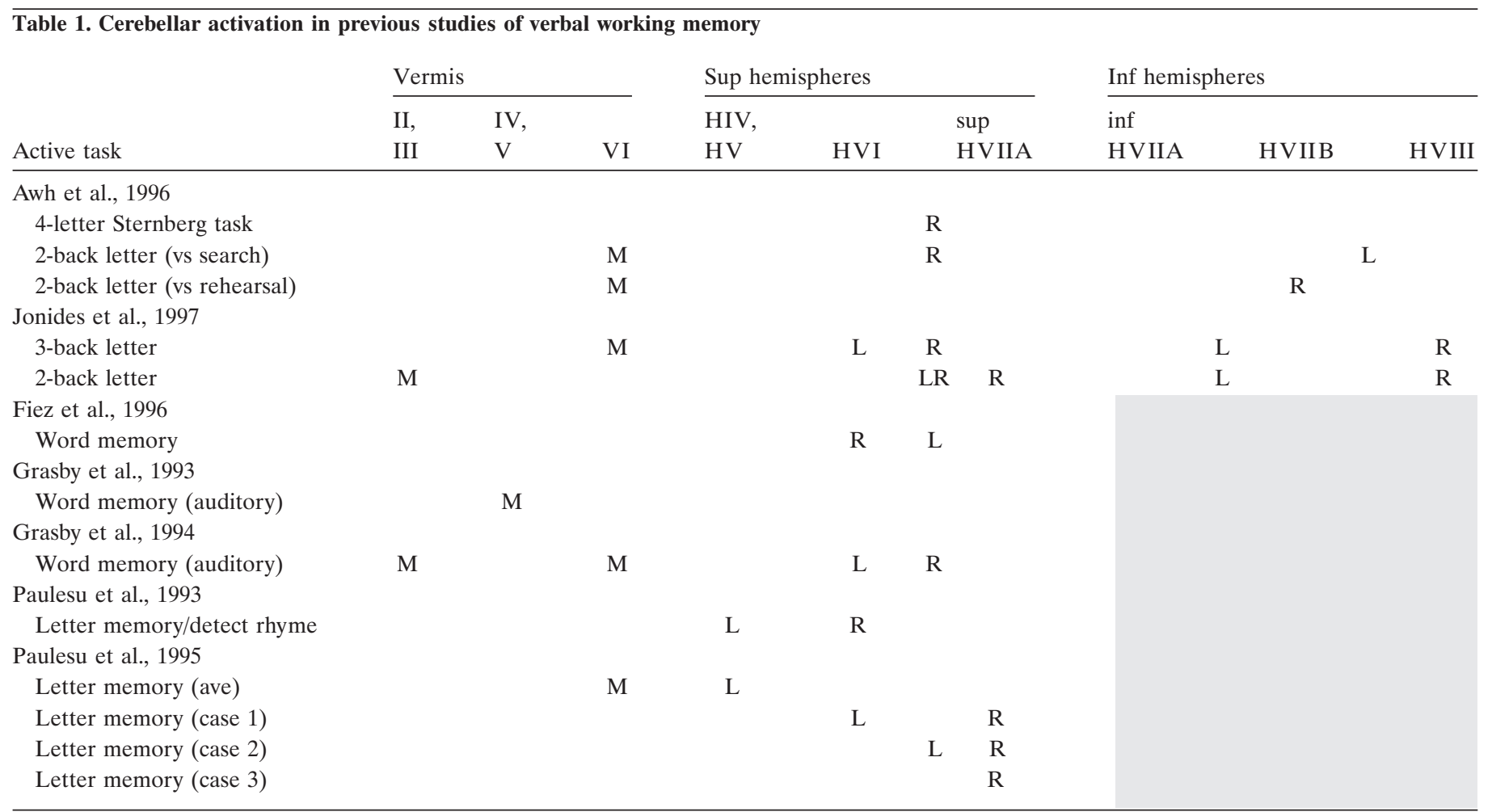

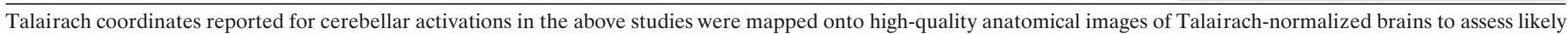

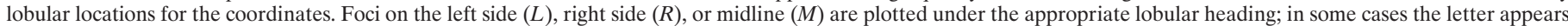

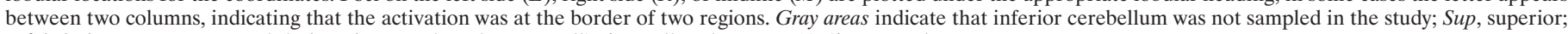
Inf, inferior. Roman numeral designations are based on Larsell's (Larsell and Jansen, 1972) nomenclature.

subject, the average $Z$ score value of all the pixels within an ROI was computed.

To assess whether the effects of load differed between the workingmemory and motoric rehearsal tasks, we obtained for each subject the average signal intensities during the high and low load conditions for each task. A three-factor repeated-measures ANOVA, with factors of slice, load, and task, was calculated for each lobule (right, left, and midline structures treated separately). A main effect of load in the absence of a load $\times$ task interaction indicated that articulatory rehearsal, regardless of memory requirements, is sufficient to produce activation in the lobule. In contrast, the presence of a load $\times$ task interaction indicated that the changes in activation caused by load were different for the working-memory and motoric rehearsal tasks. Furthermore, the interaction of slice with either of these effects indicated a dependence on the anterior-posterior position within the lobule. To minimize the number of statistical tests, we did not perform comparisons on slices unless there was a significant slice interaction in the ANOVA.

To compare the anatomical distribution of our activations with results of previous imaging studies of working memory (Table 1), we normalized the magnetic resonance brain volume data of five healthy individuals into the coordinate system of Talairach and Tournoux (1988) using a method described by Desmond and Lim (1997). Each Talairach coordinate that was classified as originating from within the cerebellum was mapped onto a high quality T1-weighted coronal and sagittal section from each of the five normalized brains, and the likely lobular location of the activation was assessed.

\section{RESULTS}

Behavioral responses were counted only if they occurred within $1.5 \mathrm{sec}$ from the onset of the probe stimulus. For the low load condition in the working-memory task, subjects had a $95.8 \%$ hit rate and $0 \%$ false alarm rate. For the high load condition, subjects had a hit rate of $57.3 \%$ (although for some trials, subjects responded correctly after the $1.5 \mathrm{sec}$ response window) and a $7.3 \%$ false alarm rate. A paired $t$ test on the corrected scores (hits minus false alarms) for high and low load conditions was signifi- cant $\left[t_{(7)}=8.0735 ; p<0.0001\right]$. These data indicate that the high load condition was more challenging than was the low load condition.

For the finger-tapping task, activation in the cerebellar hemispheres was primarily on the right side, ipsilateral to the hand that was performing the task (Figs. 4-6). The activation was focused in HIV, HV (i.e., anterior quadrangular lobule), and HVI (posterior quadrangular lobule). The magnitude of the activation in these lobules appeared to be maximal on slice 3 and progressively decreased in either the anterior or posterior direction. A second, considerably weaker, focus of activation was found in HV III (i.e., biventral lobule) bilaterally, with greater magnitude on the right side. Activation was also observed in the vermis both anteriorly in lobules IV and V (i.e., culmen) and posteriorly in lobule VI (i.e., declive). Increased activation was not observed in the deep nuclei. In fact, there appeared to be a small but significant decrease in activation in the most inferior portion of the right dentate nucleus in slices 3 and 4 .

For the high relative to low load conditions in the workingmemory task, several activation foci were observed, as illustrated in Figures 4 and 7. In the right hemisphere, an inferior focus was evident in HVIIB (i.e., gracile lobule) and to a lesser degree in HVIII; these are especially prominent in slices 3 and 4 of Figure 4. A superior activation was observed posteriorly in HVI and superior HVIIA (i.e., superior semilunar lobule), which can be seen in slices 5 and 6 of Figure 4. A similar activation in superior HVIIA was observed in the left hemisphere. Activation of the posterior vermis in lobules VI, superior VIIA (folium vermis), and inferior VIIA and VIIB (tuber vermis) is also evident in slices 4-6 of Figure 4. No activations were observed in the deep cerebellar nuclei. 


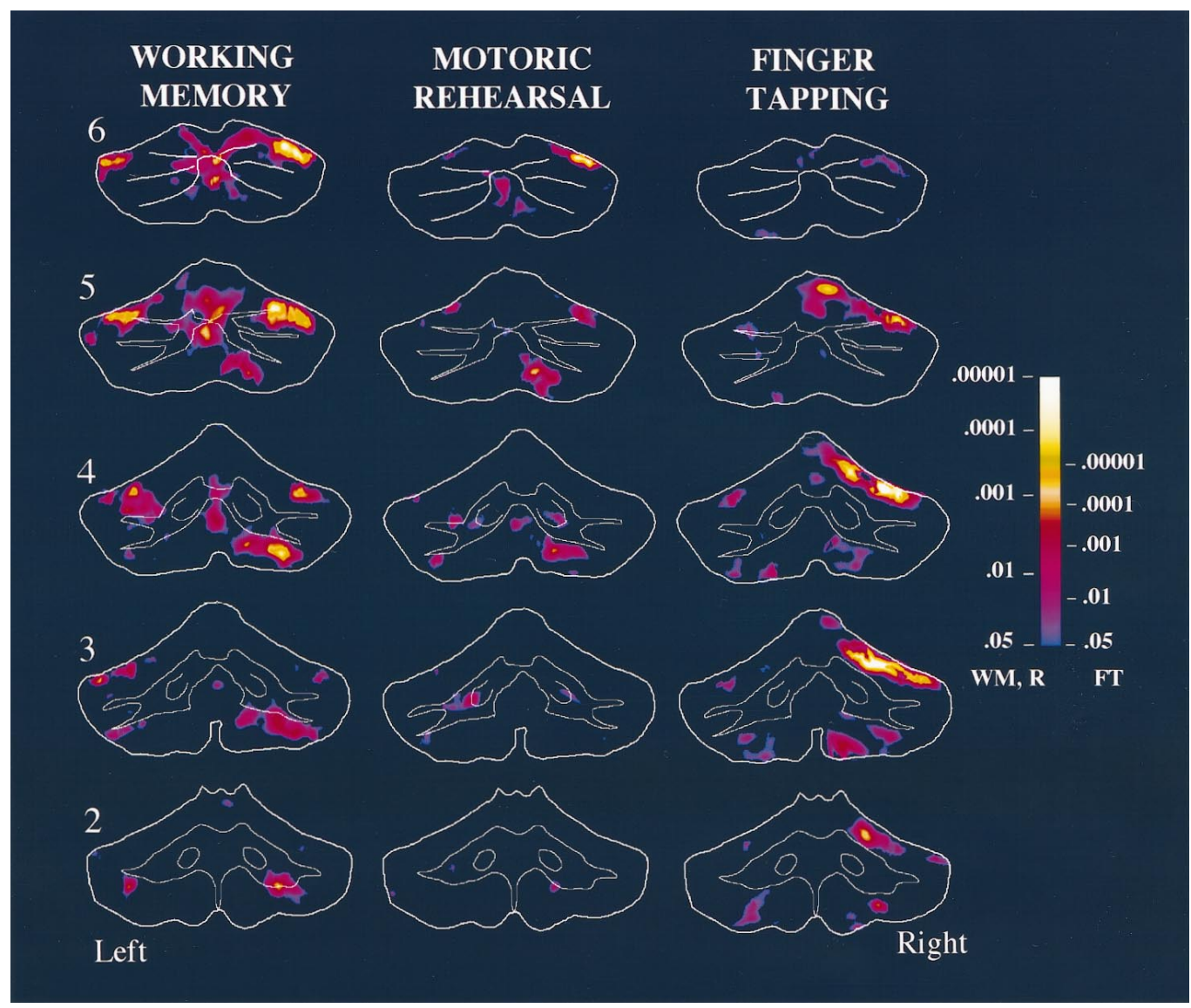

Figure 4. Averaged fMRI activation in slices 2-6 for the working-memory, motoric rehearsal, and finger-tapping tasks. Sections represent oblique coronal slices taken parallel to the dorsal surface of the brain stem, as illustrated in Figure 2, and slice numbers appear on the left. Slice 1, which was the most anterior slice, exhibited almost no activation and was therefore omitted from the figure. The maps for working memory and motoric rehearsal were averaged across eight subjects, whereas finger tapping was averaged across five subjects. Regions depicted in color represent areas that exhibited increased activation in high relative to low load conditions (in working memory and motoric rehearsal) or during finger tapping relative to rest. Decreases in activation during high load or finger tapping relative to their contrasting conditions were negligible and so are not depicted in this figure or in Figure 5. The color scale on the right represents the significance levels (one-tailed $p$ values) of averaged $Z$ scores and is scaled differently for finger tapping than for working memory and motoric rehearsal. The right side of the brain is depicted on the right. WM, Working memory; $R$, motoric rehearsal; FT, finger tapping.

For the motoric rehearsal task, increases in activation were also observed in inferior and superior portions of the cerebellar hemispheres and in posterior vermis, but these were lower in magnitude and did not occur in the same locations of activation observed for the working-memory task. Inspection of Figures 4 and 7 reveals that the inferior focus of activation in the right hemisphere was primarily confined to HVIII, whereas working memory activated HVIIB as well as HVIII. A bilateral increase in activation was observed in the inferior portion of the deep nuclei in slices 3 and 4 .

Results of the ANOVA on signal intensities, which are summarized in Figure 8, revealed a main effect of load in lobules VI and superior VIIA of the vermis. A significant slice- $\times$-load interaction was observed in the following structures: (1) right HVI, localized on slices 4-6; (2) left superior HVIIA, localized on slices 3-5; (3) right HIX, localized on slice 3; and (4) left HVIIB, localized on slice 5 only. In all cases except for left HVIIB, greater signal magnitude was observed for high relative to low load (this exception is not depicted in Fig. 8). The absence of any interaction with task in the above regions indicates that rehearsal load, regardless of the presence of working memory, influenced the amount of activation. In contrast to these regions, right
HVIIB exhibited a significant task- $\times$-load interaction. Subsequent comparisons for this lobule revealed that there was no difference in load for the motoric rehearsal task but that high load was significantly greater than low load for the working-memory task. Significant effects were not observed for the deep nuclei.

\section{DISCUSSION}

The finger-tapping activations coincide well with findings from mapping experiments in animals (Adrian, 1943; Snider and Stowell, 1944; Welker et al., 1988). These investigators reported forelimb responses ipsilaterally in the anterior lobe, with the hand representation close to the border of $\mathrm{HIV} / \mathrm{HV}$ and $\mathrm{HVI}$. A second bilateral map was found in the paramedian lobule, corresponding to human gracile HVIIB and lateral biventral (HVIII) lobules. Our results indicate strong activation in lobules $\mathrm{HIV} / \mathrm{HV}$ and HVI during finger tapping, which is consistent with the findings of a previous positron emission tomography (PET) study (Fox et al., 1985). We also observed activation in HVIII, with greater activation occurring ipsilaterally. Neither the present study nor the study of Fox et al. (1985) found increased activation in the deep nuclei during finger tapping, and our results in fact 


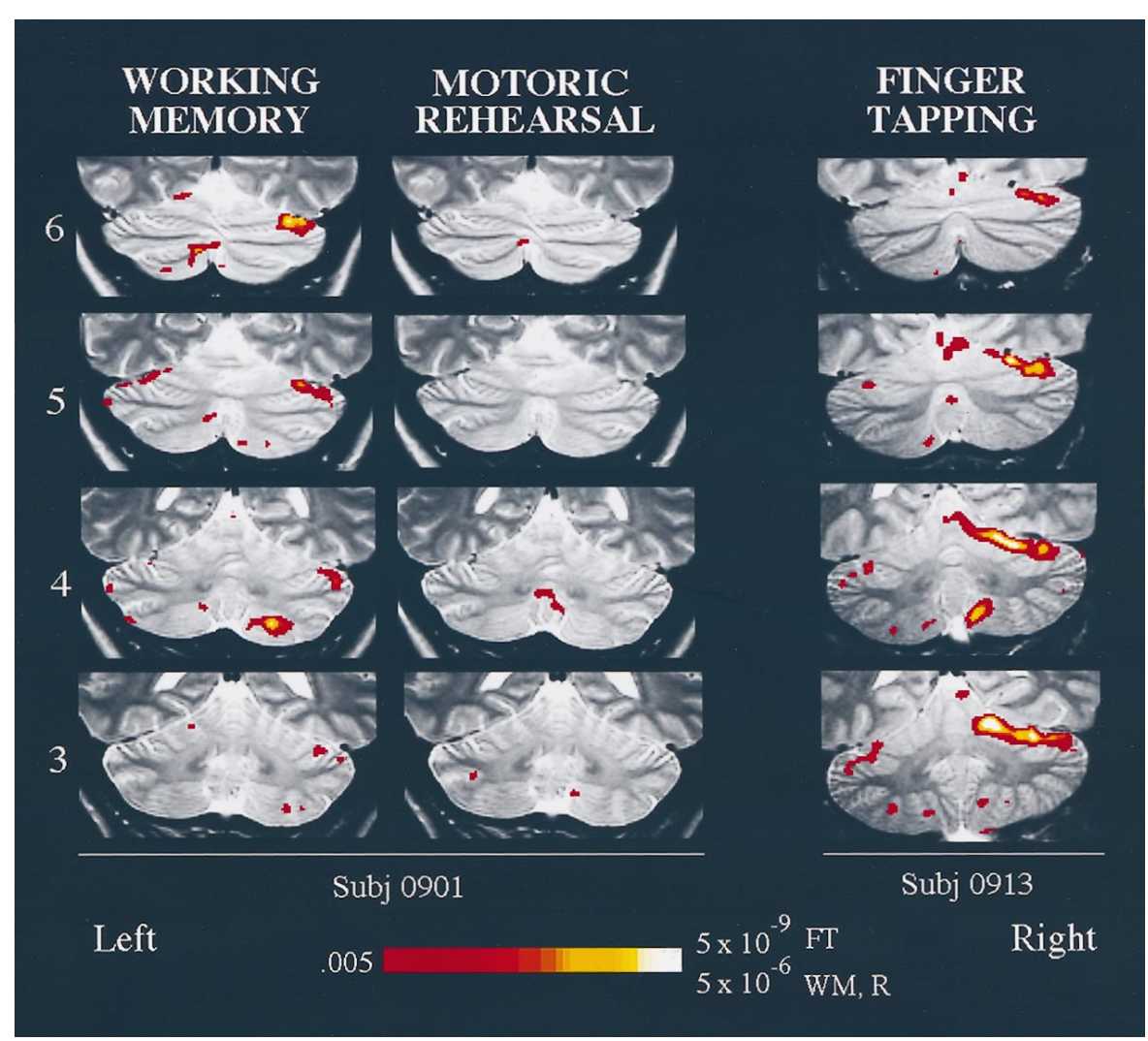

Figure 5. Functional activation maps for individual subjects, overlaid on T2-weighted anatomy images. Activation obtained from the same subject for working-memory and motoric rehearsal tasks is illustrated on the left. The finger-tapping activation for a different subject is on the right. Slice numbers (3-6; see Fig. 2) appear on the left. The color scale at the bottom represents the significance levels (one-tailed $p$ values) of $Z$ scores and is scaled differently for finger tapping than for working memory and motoric rehearsal. Color voxels represent regions that exhibited increased activation during high versus low load for the workingmemory and motoric rehearsal tasks or during finger tapping versus rest for the finger-tapping task. The right side of the brain is depicted on the right. $W M$, Working memory; $R$, motoric rehearsal; $F T$, finger tapping.

suggest an ipsilateral decrease in activation in inferior portions of the dentate nucleus.

For the working-memory task, but not the motoric rehearsal task, increases in activation occurred in right HVIIB during the high relative to low load condition. We conclude, therefore, that activation in this lobule during working memory cannot be accounted for by articulatory motor differences in rehearsal load but rather is specific to the internally guided processes of working memory. Significant differences in load, regardless of workingmemory requirement, were notable in two other locations, posterior vermis (VI and superior VIIA) and bilaterally in the superior cerebellar hemisphere (HVI/superior HVIIA). In comparing these results with the estimated lobular organization of cerebellar activation from previous studies (Table 1), it is evident that activation in vermian lobule VI and bilateral $\mathrm{HVI}$ /superior HVIIA is frequently observed and that activation in HVIIB/ HVIII is also present in the few experiments that included inferior cerebellar hemispheres in their field of view. Although the data compiled from Table 1 are approximate (because only peak activation foci were available for comparisons, and data from inferior cerebellar cortex are sparse), previous studies of verbal working memory and the present study exhibit common patterns of cerebellar activation.

To interpret these results, we draw on the neuroanatomical literature derived from animal studies, current theory of working memory from cognitive psychology, and hypotheses regarding the function of the cerebellum. Considering first the likely origin of the cerebellar hemispheric activation, it is necessary to make inferences from separate studies of pontocerebellar and corticopontine projections. Evidence from horseradish peroxidasetracing experiments in monkeys suggests that mossy fiber afferents to the paramedian lobule are derived from the lateral portions of the pontine nuclei, whereas afferents to the simplex lobule and crus I of the ansiform lobule (HVI and superior HVIIA, respectively) are derived from more medial pontine regions (Brodal, 1979, 1981, 1982; Glickstein et al., 1994). The lateral pontine nuclei, in turn, receive much of their input from temporal and parietal association areas of the cerebral cortex, and the medial pontine nuclei receive their strongest projections from frontal cortex, including prefrontal areas (Nyby and Jansen, 1951; Brodal, 1978, 1981; Ungerleider et al., 1984; Schmahmann and Pandya, 1989, 1991, 1993, 1995, 1997; Schmahmann, 1996). Based on this evidence, we will assume in the model below that HVIIB activation reflects inputs originating from temporal and parietal regions and that $\mathrm{HVI} /$ superior HVIIA activation represents inputs from the frontal lobe.

The significance of these paths can be interpreted within the current framework for working memory (Baddeley, 1992) in which a phonological loop is hypothesized to permit the shortterm maintenance of verbal information. This loop is assumed to be comprised of two components, a phonological store, which can hold speech-related information for 1-2 sec, and an articulatory control process, which serves to subvocally refresh the contents of the phonological store. Behavioral evidence suggests that these two processes are independent (Longoni et al., 1993), and a PET study of verbal working memory made use of this independence to assess the likely neural correlates of these processes in the cerebral cortex (Paulesu et al., 1993). The results of the task subtractions in the latter study localized the phonological store in the left supramarginal gyrus (Brodmann area 40) and the articulatory control process in Broca's area (Brodmann area 44/45).

In light of the evidence discussed above, as well as the activation results of the present study, we postulate that the temporaland parietal-derived information that we assume is received by the inferior cerebellar cortex in HVIIB reflects input from the phonological store and that the frontal-derived information that 


\section{FINGER TAPPING}

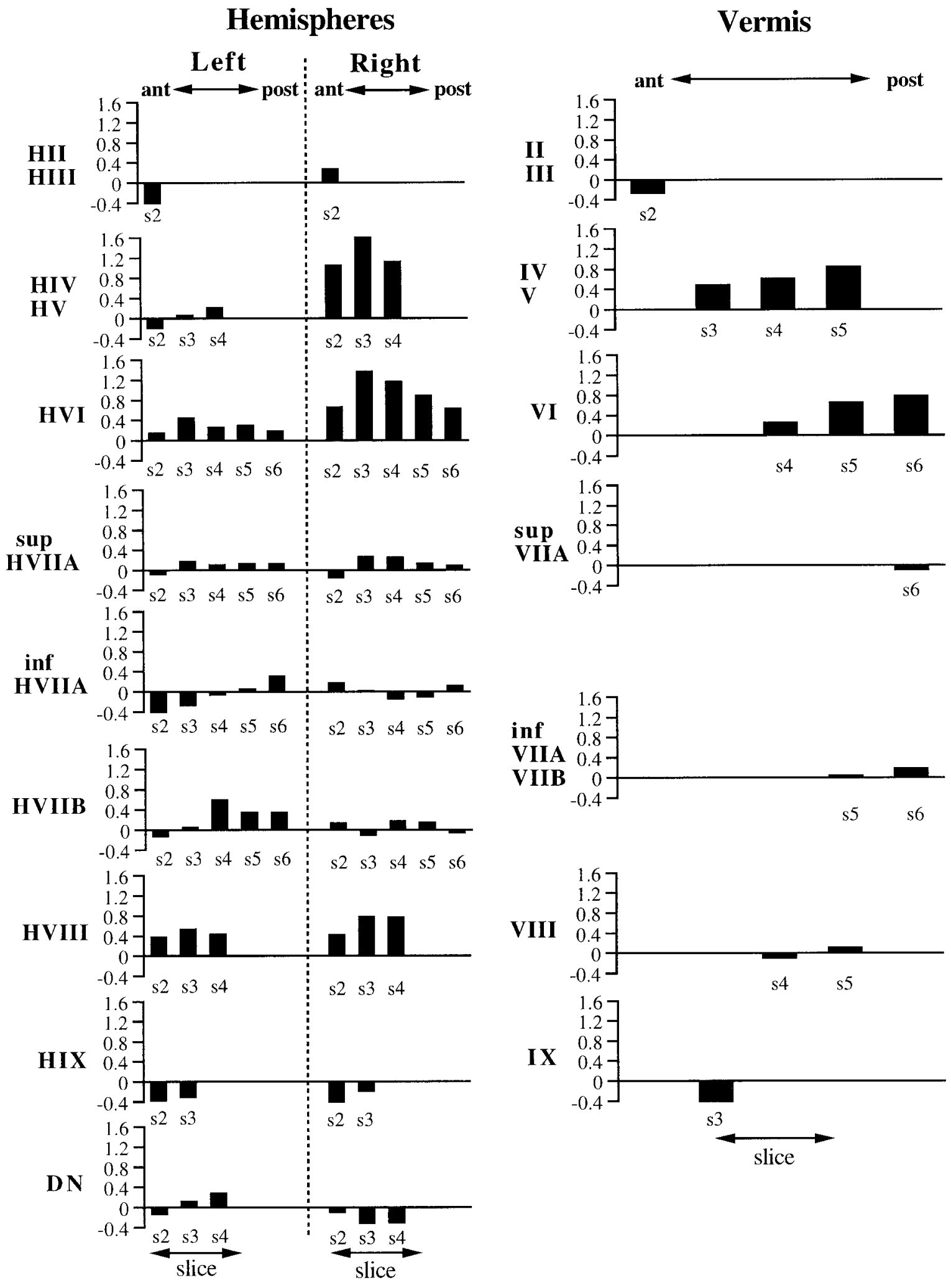

Figure 6. ROI results for the finger-tapping task, representing the activations from five subjects. The $y$-axis in each graph represents the average $Z$ score values obtained from the ROI. The name of the ROI appears next to the $y$-axis, with ROIs from the cerebellar hemispheres depicted on the left and ROIs from the vermis on the right. The $x$-axis denotes the anterior-posterior dimension of the ROI, which corresponds to the slice number (denoted $s 2-s 6$; see Fig. 2). The absence of a slice number on the $x$-axis means that the ROI did not appear on that slice. 
WORKING MEMORY vs. MOTORIC REHEARSAL

Hemispheres
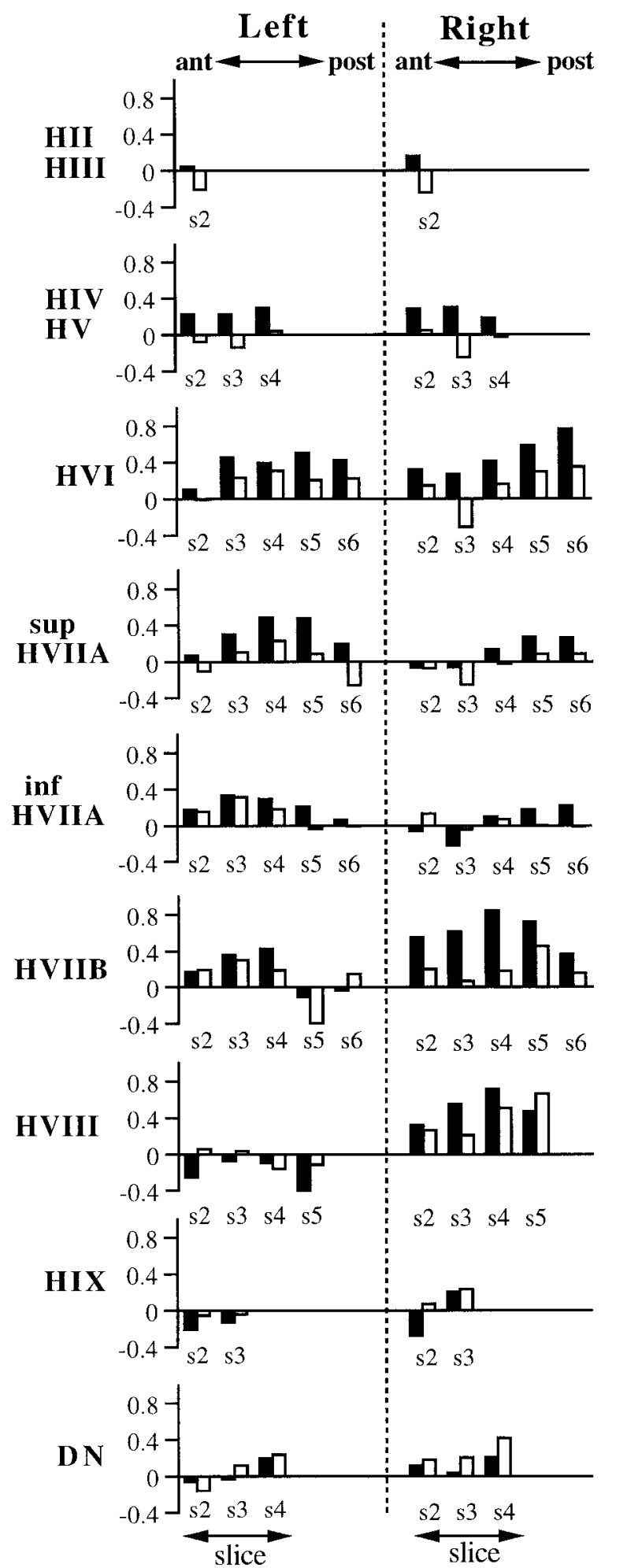

Vermis
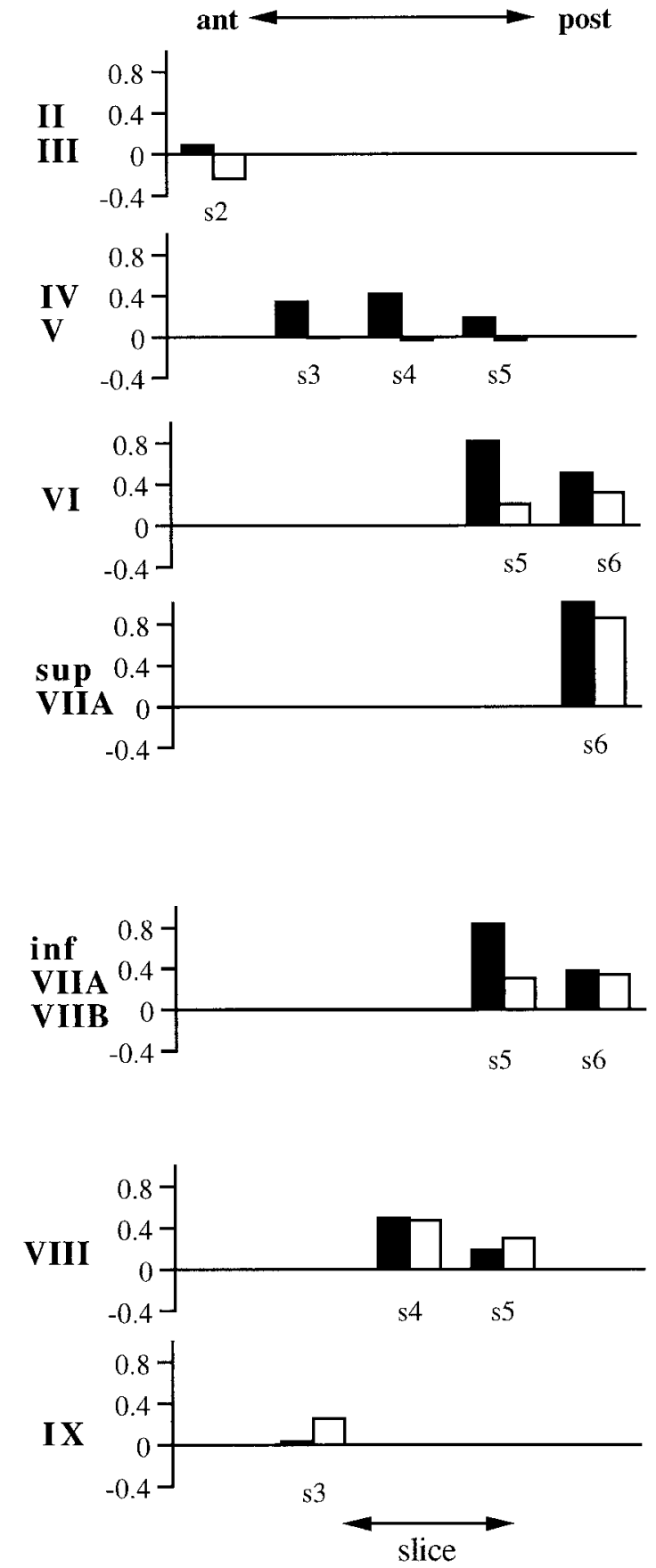

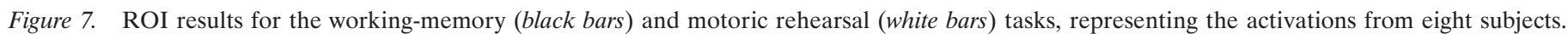
The organization of the figure is the same as that described for Figure 6. 


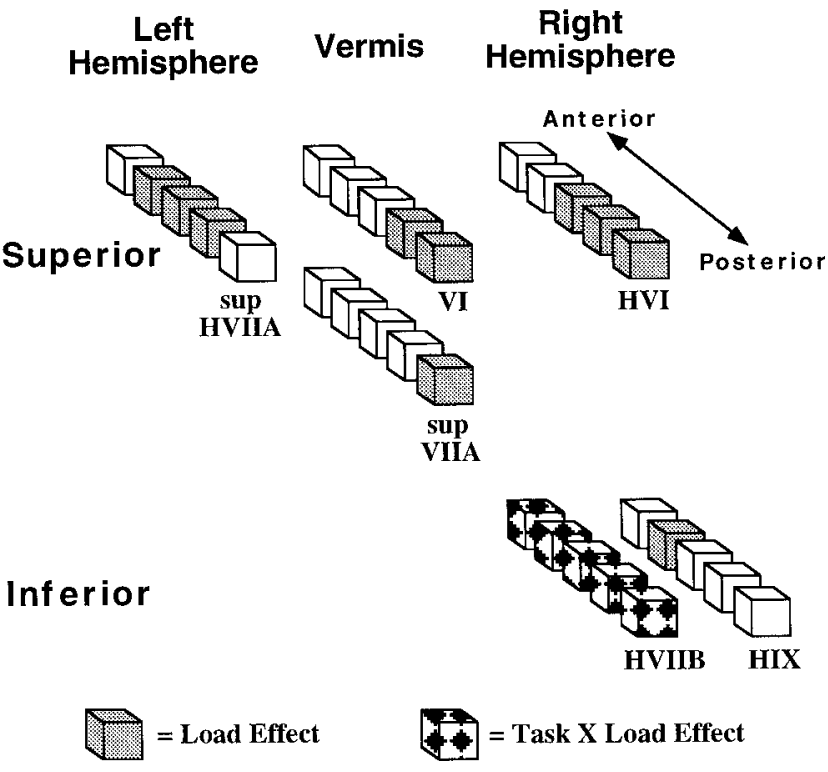

Figure 8. Results of ANOVA on cerebellar lobular activation during working-memory and motoric rehearsal tasks. Each cube within each linear set of cubes represents a slice position ranging from the most anterior (slice 2) to the most posterior (slice 6) location. The figure summarizes the regions that exhibited a significant effect of load (gray cubes, with high greater than low load) or a task- $\times$-load interaction ( patterned cubes, with high greater than low load for the working-memory but not for the motoric rehearsal task). Because a significant load- $X$-slice interaction was present for left superior HVIIA, right HVI, and right HIX, only the slices at which the load difference was significant are shaded. For the remaining lobules, no interaction with slice was observed, so all slices on which the lobule is found are shaded.

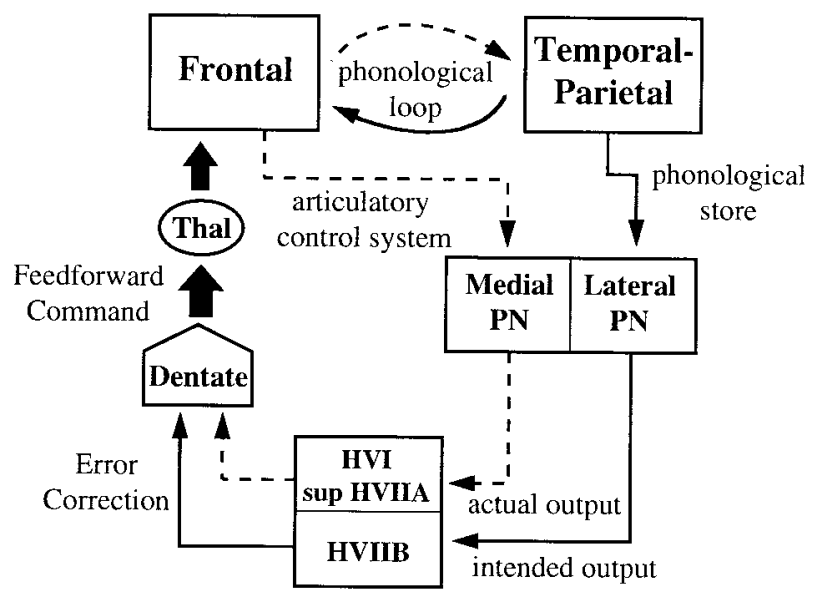

Figure 9. Model of cerebrocerebellar circuit proposed to be involved in verbal working memory. In addition to the phonological loop between frontal lobe structures (such as Broca's area, comprising the articulatory control system and represented by a dashed line) and temporal-parietal structures (such as the supramarginal gyrus, comprising the phonological store and represented by a solid line), a parallel path from these structures enters the cerebellar cortex via the pontine nuclei. Discrepancies between the actual and intended phonological output are computed and used to update a feedforward articulatory rehearsal command to the frontal cortex via dentatothalamic projections. PN, Pontine nuclei; Thal, thalamus.

is assumed to reach the superior cerebellar cortex reflects input from the articulatory control process. The model is illustrated in Figure 9 , where it can be seen that the function of the cerebellum during verbal working memory is to compare the output of subvocal articulation with the contents of the phonological store. In this model, performing a single iteration of rehearsing verbal stimuli, such as the set of six letters in the high load workingmemory condition, can be viewed as completing a "motor" trajectory, in which the desired trajectory is represented in the phonological store. Smooth and rapid update of the phonological store would require predictive control of the articulatory control process, just as predictive control is required for rapidly coordinated movements of the limbs. Thus, discrepancies between the desired and actual trajectories are hypothesized to result in error correction and subsequent update of a feedforward command (e.g., Kawato et al., 1987; Kawato and Gomi, 1992). Although Figures 4 and 7 suggest a somewhat greater activation of the superior cerebellar cortex during the working-memory task than during the motoric rehearsal task, the presence of a significant load effect but the lack of a significant task $\times$ load interaction in the superior hemispheres suggest, according to our model, that the articulatory control process is engaged by the motoric rehearsal task as well as by the working-memory task. Furthermore, the presence of bilateral superior cerebellar activation may be explained by the fact that right, as well as left, frontal lobe activation is observed in tasks involving verbal working memory (see Fiez et al., 1996).

The feedforward command depicted in Figure 9 is assumed to originate from the dentate nucleus, a structure which, along with the lateral cerebellum, has greatly increased in size during hominid evolution (Leiner et al., 1986) and has been shown via transneuronal-tracing methods to project via the thalamus to prefrontal cortical areas (Middleton and Strick, 1994). Our data did not reveal much activation in the dentate nuclei during the working-memory task, and in fact, the motoric rehearsal task, which showed the least amount of cerebellar cortical activation, exhibited the strongest increase in the dentate. One possible explanation for weak dentate activation during working memory is that dentate neurons have a low response threshold for this task, thereby producing nearly equal activation magnitudes for high and low load conditions. We investigated this possibility by alternating high and no working-memory load conditions (with the no-load condition consisting of a visual array of six \# symbols and a simple instruction to press or not to press the response switch during the probe presentation period). Our results thus far have not revealed additional dentate activation under these conditions (Desmond et al., 1996).

A second possibility is that dentate activation is more readily apparent under higher magnetic field strength. The two studies that have shown prominent dentate activation as measured by fMRI (Kim et al., 1994; Gao et al., 1996) used field strengths greater than the present $1.5 \mathrm{~T}$. However, this explanation seems unlikely given that Gao et al. (1996) also exhibited insignificant dentate activation during a fine finger movement task but showed strong dentate activation during tactile discrimination. Thus, a more likely explanation for the lack of dentate activation during our working-memory task is that, at the level of single dentate neurons, the firing pattern of the cells precluded sufficient alterations in the flow of oxyhemoglobin to produce measurable signals. However, this does not necessarily mean that working memory has a weak influence on dentate neurons. Discharge patterns of deep cerebellar nuclei can be a complex combination of increased and decreased firing, even during slow tracking movements (Schieber and Thach, 1985). Such patterns may be less favorable for inducing blood flow changes than are sustained 
periods of firing. The lack of deep nuclear activation during finger movement in the present study and previous studies is similarly puzzling, given that modulation of unit activity is known to occur during such movements (Thach et al., 1982, 1993; Wetts et al., 1985; van Kan et al., 1993).

Although not included in Figure 9, activation in the posterior vermis was also significantly greater during high relative to low load. Given the known involvement of the posterior vermis in eye movements (Fujikado and Noda, 1987; Noda and Fujikado, 1987; Yamada and Noda, 1987; Ohtsuka and Noda, 1992), one possible explanation for the vermal activation is that there were greater eye movements involved with reading six letters versus reading one letter. However if this was the case, it is not clear why the motoric rehearsal task, with the stimulus array repeatedly presented throughout the duration of the trial rather than just at the beginning, did not exhibit more oculomotor-related activation than did the working-memory task.

Our results suggest that the cerebellum is involved in the fundamental cognitive process of working memory, and the lobular activation patterns we report serve as a prediction of where damage to the cerebellum is most likely to affect working memory. Our interpretation of cerebellar activation as depicted in Figure 9 reflects cerebellar computations that are qualitatively similar to those hypothesized to occur during skilled limb movements (see Ito, 1993) as well as simpler forms of motor learning (see Raymond et al., 1996). Whether such interpretations can be readily applied to other instances of cognitively derived cerebellar activation remains to be determined.

\section{REFERENCES}

Adrian ED (1943) Afferent areas in the cerebellum connected with the limbs. Brain 66:289-315.

Allen G, Buxton RB, Wong EC, Courchesne E (1997) Attention activation of the cerebellum independent of motor involvement. Science 275:1940-1943

Awh E, Jonides J, Smith EE, Schumacher EH, Koeppe RA, Katz S (1996) Dissociation of storage and rehearsal in verbal working memory: evidence from positron emission tomography. Psychol Sci 7:25-31.

Baddeley A (1992) Working memory. Science 255:556-559.

Brodal A (1981) Neurological anatomy in relation to clinical medicine, Ed 3. New York: Oxford UP.

Brodal P (1978) The corticopontine projection in the rhesus monkey. Origin and principles of organization. Brain 101:251-283.

Brodal P (1979) The ponto-cerebellar projection in the rhesus monkey: an experimental study with retrograde axonal transport of horseradish peroxidase. Neuroscience 4:193-208.

Brodal P (1982) Further observations on the cerebellar projections from the pontine nuclei and the nucleus reticularis tegmenti pontis in the rhesus monkey. J Comp Neurol 204:44-55.

Cohen JD, MacWhinney B, Flatt M, Provost J (1993) PsyScope: a new graphic interactive environment for designing psychology experiments. Behav Res Methods Instr Comp 25:257-271.

Courchesne E, Press GA, Murakami J, Berthoty D, Grafe M, Wiley CA, Hesselink JR (1989) The cerebellum in sagittal plane-anatomic-MR correlation: 1. the vermis. AJR Am J Roentgenol 153:829-835.

Desmond JE, Lim KO (1997) On- and offline Talairach registration for structural and functional MRI studies. Hum Brain Mapp 5:58-73.

Desmond JE, Sum JM, Wagner AD, Demb JB, Shear PK, Glover GH, Gabrieli JDE, Morrell MJ (1995) Functional MRI measurement of language lateralization in Wada-tested patients. Brain 118:1411-1419.

Desmond JE, Gabrieli JDE, Sobel N, Rabin LA, Wagner AD, Seger CA, Glover GH (1996) An fMRI study of frontal cortex and cerebellum during semantic and working memory tasks. Soc Neurosci Abstr 22:1111.

Duvernoy HM (1995) The human brain stem and cerebellum: surface, structure, vascularization, and three-dimensional sectional anatomy with MRI. New York: Springer.

Fiez JA (1996) Cerebellar contributions to cognition. Neuron 16:13-15.

Fiez JA, Raife EA, Balota DA, Schwarz JP, Raichle ME, Petersen SE
(1996) A positron emission tomography study of the short-term maintenance of verbal information. J Neurosci 16:808-822.

Fox PT, Raichle ME, Thach WT (1985) Functional mapping of the human cerebellum with positron emission tomography. Proc Natl Acad Sci USA 82:7462-7466.

Friston KJ, Jezzard P, Turner R (1994) Analysis of functional MRI time-series. Hum Brain Mapp 1:153-171.

Fujikado T, Noda H (1987) Saccadic eye movements evoked by microstimulation of lobule VII of the cerebellar vermis of macaque monkeys. J Physiol (Lond) 394:573-594.

Gao JH, Parsons LM, Bower JM, Xiong J, Li J, Fox PT (1996) Cerebellum implicated in sensory acquisition and discrimination rather than motor control. Science 272:545-547.

Glickstein M, Gerrits N, Kralj-Hans I, Mercier B, Stein J, Voogd J (1994) Visual pontocerebellar projections in the macaque. J Comp Neurol 349:51-72.

Grasby PM, Frith CD, Friston KJ, Bench C, Frackowiak RS, Dolan RJ (1993) Functional mapping of brain areas implicated in auditoryverbal memory function. Brain 116:1-20.

Grasby PM, Frith CD, Friston KJ, Simpson J, Fletcher PC, Frackowiak RS, Dolan RJ (1994) A graded task approach to the functional mapping of brain areas implicated in auditory-verbal memory. Brain 117:1271-1282.

Ito M (1993) Movement and thought: identical control mechanisms by the cerebellum. Trends Neurosci 16:448-450, 453-454.

Jenkins IH, Frackowiak RS (1993) Functional studies of the human cerebellum with positron emission tomography. Rev Neurol (Paris) 149:647-653.

Jonides J, Schumacher EH, Smith EE, Lauber EJ, Awh E, Minoshima S, Koeppe RA (1997) Verbal working memory load affects regional brain activation as measured by PET. J Cognit Neurosci 9:462-475.

Just MA, Carpenter PA (1992) A capacity theory of comprehension: individual differences in working memory. Psychol Rev 99:122-149.

Kawato M, Gomi H (1992) The cerebellum and VOR/OKR learning models. Trends Neurosci 15:445-453.

Kawato M, Furukawa K, Suzuki R (1987) A hierarchical neural-network model for control and learning of voluntary movement. Biol Cybern 57:169-185.

Kim SG, Ugurbil K, Strick PL (1994) Activation of a cerebellar output nucleus during cognitive processing. Science 265:949-951.

Larsell O, Jansen J (1972) The comparative anatomy and histology of the cerebellum: the human cerebellum, cerebellar connections, and cerebellar cortex. Minneapolis: University of Minnesota.

Leiner HC, Leiner AL, Dow RS (1986) Does the cerebellum contribute to mental skills? Behav Neurosci 100:443-454.

Leiner HC, Leiner AL, Dow RS (1993) Cognitive and language functions of the human cerebellum. Trends Neurosci 16:444-447.

Leiner HC, Leiner AL, Dow RS (1995) The underestimated cerebellum. Hum Brain Mapp 2:244-254.

Longoni AM, Richardson JT, Aiello A (1993) Articulatory rehearsal and phonological storage in working memory. Mem Cognit 21:11-22.

Meyer CH, Hu BS, Nishimura DG, Macovski A (1992) Fast spiral coronary artery imaging. Magn Reson Med 28:202-213.

Middleton FA, Strick PL (1994) Anatomical evidence for cerebellar and basal ganglia involvement in higher cognitive function. Science 266:458-461.

Noda H, Fujikado T (1987) Topography of the oculomotor area of the cerebellar vermis in macaques as determined by microstimulation. J Neurophysiol 58:359-378.

Nyby O, Jansen J (1951) An experimental investigation of the corticopontine projection in Macaca mulatta. Skrifter utgitt av det Norske Vedenskapsakademie: Oslo. Mat Naturv Klasse 3:1-47.

Ohtsuka K, Noda H (1992) Burst discharges of mossy fibers in the oculomotor vermis of macaque monkeys during saccadic eye movements. Neurosci Res 15:102-114.

Paulesu E, Frith CD, Frackowiak RS (1993) The neural correlates of the verbal component of working memory. Nature 362:342-345.

Paulesu E, Connelly A, Frith CD, Friston KJ, Heather J, Myers R, Gadian DG, Frackowiak RS (1995) Functional MR imaging correlations with positron emission tomography. Initial experience using a cognitive activation paradigm on verbal working memory. Neuroimaging Clin N Am 5:207-225.

Press GA, Murakami J, Courchesne E, Berthoty DP, Grafe M, Wiley CA, Hesselink JR (1989) The cerebellum in sagittal plane-anatomic-MR 
correlation: 2. the cerebellar hemispheres. AJR Am J Roentgenol 153:837-846.

Press GA, Murakami JW, Courchesne E, Grafe M, Hesselink JR (1990) The cerebellum: 3 . anatomic-MR correlation in the coronal plane. AJR Am J Roentgenol 154:593-602.

Raymond JL, Lisberger SG, Mauk MD (1996) The cerebellum: a neuronal learning machine? Science 272:1126-1131.

Schieber MH, Thach Jr WT (1985) Trained slow tracking. II. Bidirectional discharge patterns of cerebellar nuclear, motor cortex, and spindle afferent neurons. J Neurophysiol 54:1228-1270.

Schmahmann JD (1996) From movement to thought: anatomic substrates of the cerebellar contribution to cognitive processing. Hum Brain Mapp 4:174-198.

Schmahmann JD, Pandya DN (1989) Anatomical investigation of projections to the basis pontis from posterior parietal association cortices in rhesus monkey. J Comp Neurol 289:53-73.

Schmahmann JD, Pandya DN (1991) Projections to the basis pontis from the superior temporal sulcus and superior temporal region in the rhesus monkey. J Comp Neurol 308:224-248.

Schmahmann JD, Pandya DN (1993) Prelunate, occipitotemporal, and parahippocampal projections to the basis pontis in rhesus monkey. J Comp Neurol 337:94-112.

Schmahmann JD, Pandya DN (1995) Prefrontal cortex projections to the basilar pons in rhesus monkey: implications for the cerebellar contribution to higher function. Neurosci Lett 199:175-178.

Schmahmann JD, Pandya DN (1997) Anatomic organization of the basi- lar pontine projections from prefrontal cortices in rhesus monkey. J Neurosci 17:438-458.

Snider RS, Stowell A (1944) Receiving areas of the tactile, auditory, and visual systems of the cerebellum. J Neurophysiol 7:331-358.

Talairach J, Tournoux PA (1988) A co-planar stereotaxic atlas of the human brain. Stuttgart, Germany: Thieme.

Thach WT, Perry JG, Schieber MH (1982) Cerebellar output: body maps and muscle spindles. Exp Brain Res [Suppl] 6:440-453.

Thach WT, Perry JG, Kane SA, Goodkin HP (1993) Cerebellar nuclei: rapid alternating movement, motor somatotopy, and a mechanism for the control of muscle synergy. Rev Neurol (Paris) 149:607-628.

Ungerleider LG, Desimone R, Galkin TW, Mishkin M (1984) Subcortical projections of area MT in the macaque. J Comp Neurol 223:368-386.

van Kan PL, Houk JC, Gibson AR (1993) Output organization of intermediate cerebellum of the monkey. J Neurophysiol 69:57-73.

Welker W, Blair C, Shambes GM (1988) Somatosensory projections of cerebellar granule cell layer of giant bushbaby, Galago crassicaudatus. Brain Behav Evol 31:150-160.

Wetts R, Kalaska JF, Smith AM (1985) Cerebellar nuclear cell activity during antagonist cocontraction and reciprocal inhibition of forearm muscles. J Neurophysiol 54:231-244.

Yamada J, Noda H (1987) Afferent and efferent connections of the oculomotor cerebellar vermis in the macaque monkey. J Comp Neurol 265:224-241. 